УАK 351

ББК 67.401.11

DOI 10.22394/1682-2358-2017-5-20-31

A.N. Romantsov, Doctor of Sciences (Economics), Professor of the Organization Manazement Department, Povolzbsky Institute of Manazement named after P.A. Stolypin, Branch of the Russian Presidential Academy of National Economy and Public Administration

A.V. Fomenko, Doctor of Sciences (Economics), Professor, Head of the Organization Manazement Department, Povolzhsky Institute of Management named after P.A. Stolypin, Branch of the Russian Presidential Academy of National Economy and Public Administration

\section{THE ROLE OF PUBLIC ADMINISTRATION BODIES IN PLANNING LABOR PRODUCTIVITY GROWTH}

The role of government bodies in improving labor productivity by solving the problem of planning labor productivity growth is defined. Developing and implementing appropriate government programs, implementing a government plan to increase labor productivity and creating and modernizing high-performance jobs are considered.

Key words and word-combinations. economic restructuring, technological renewal, labor productivity, productivity improvement program.
A.H. Романиов, доктор экономических наук, профессор кафедри менеджмента организаиии Поволжского института управления им. П.А. Стольпина - филиала Российской академии народного хозяйства и государственной службы nри Президенте РФ. е-mail:romanzov@yandex.ru

А.В. Фоменко, доктор экономическихнаук, профессор, забедуюоийкафедрой менеджмента организаиии Поволжского института им. П.А. Стольгпи на - филиала Российской академиинародного хозяйсmва и государственной службб при Президенте РФ. e-mail:alexvla75@yandex.ru

\section{РО $\Lambda \mathrm{b}$ ОРГАНОВ ГОСУААРСТВЕННОГО

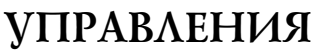 В ПААНИРОВАНИИ РОСТА ПРОИЗВОАИТЕАЬНОСТИ TPУАA*}

Аннотация. Выявляется роль органов государственного управления в повышении производительности труда через решение задачи планирования роста производительности труда. Рассматриваются проекты разработки соответствующих государственных программ, реализации правительственного плана мероприятий по обеспечению повышения производительности труда, созданию и модернизации высокопроизводительных рабочих мест.

Ключевые слова и словосочетания: структурная перестройка экономики, технологическое обновление, эффективность труда, программа повышения производительности труда.

B современных условиях целью госуАарственной политики, ориентирующей

* Публикация подготовлена в рамках исследования по гранту РГНФ №16-02-00677. 
общество на рост производительности труда, должно стать повышение динамики соџиально-экономического развития государства на основе возрастания производства материальных и духовных благ при задействовании как можно меньшего объема трудовых, организационных, материально-финансовых, природных и информационных ресурсов.

Аля правицьного восприятия такой цели следует разграничить Аинамику социально-экономического развития и динамику производительности труда, так как оценка первого явления предполагает эффективное применение всех ресурсов, а при оценке второго учитывается только эффективность использования трудовых ресурсов. В конечном итоге положительная Аинамика социацьно-экономического развития напрямую зависит от факторов роста производительности труда, среди которых следует выделить повышение уровня профессионализма и образовательного уровня кадров, их трудовую мотивацию, регулярное обновмение средств производства, активизацию инновационной деятельности, постоянную ориентацию персонала на повышение эффективности труда.

Как подчеркивает В.А. Цыганков, «...несмотря на кардинальные изменения во взглядах на оџенку эффективности труда, произошедшие в последние десятицетия, актуальность и значимость показателя производительности труда практически не подвергается сомнениям ни со стороны теоретиков экономики труда, ни со стороны практических специацистов, занятых организацией и нормированием труда на производстве» [1] .

Ориентация персонала на повышение эффективности труда имеет организационный аспект, поскольку зависит не только от деятельности в данном направлении систем корпоративного управления, но и от вклада органов государственного управления в дело повышения производительности труда на федеральном и региональном уровнях. Именно организация труда на макро-, мезо- и микроэкономическом уровнях выступает одним из кАючевых факторов роста его производительности, обеспечивая согласование кичных интересов трудящегося человека с его профессиональным и соџиальным развитием в условиях постоянного совершенствования производственной деятельности. Прежле всего следует ориентироваться на улучшение условий труда и его содержкания, что зависит от состояния среАств производства и применяемой технологии. Последние должны характеризоваться возможностью обеспечивать высокую производительность, безопасность и экологичность трудовой Аеятельности.

В настоящее время, учитывая сложившуюся ситуацию с производительностью труда в реацьном секторе экономики, следует на уровне субъектов хозяйствования в проџессе реформирования производства разрабатывать соответствующие программы по развитию организации труда.

ОАнако, как отмечает Ф.П. Косицина, «в российском реформировании реАко вспоминают о производительности труда, будто это и не критерий прогрессивности происходящей трансформации. Ааже когда пытаются выяснить причины продолжающегося роста цен, пеняют на какие угодно Аругие факто- 
ры: влияние США, происки изгнанных из России олигархов, мировой финансовый кризис и т.п.» [2]. Именно поэтому необходимость и обязательность реализации таких программ должны быть закреплены кибо законодательно, мибо постановлением Правительства РФ с передачей полномочий по контроАю их исполнения региональным властным структурам.

При реализации подобных программ в качестве одной из насущных задач следует определить повышение эффективности функционирования каждого рабочего места на основе соблюдения режима и охраны труда, создания условий Амя повышения комфортности и эстетичности рабочих мест. Крайне необходимо задействовать трудовой потенциал каждого человека с одновременным улучшением такой его качественной характеристики, как мобильность трудовых ресурсов, поскольку она становится резервом роста производительности труда при условии создания высокопроизводительных рабочих мест.

При организаџии трудового проџесса следует обратить внимание и на нормирование труда, которое в настоящее время признается составляющей управления развитием субъектов хозяйствования в экономико-техническом и соџиальном плане. ОАнако в народном хозяйстве практически не осталось профессионалов, владеющих методикой нормирования труда и имеющих опыт в вопросах повышения его производительности, так как высшие учебные заведения длительное время не выпускают специалистов по нормированию труда. Отсюда возникает потребность в развитии корпоративного образования, ибо традиџионная система образования не успевает реагировать на высокую динамику технических и технологических инноваций. Оказавшись на производстве, выпускник вуза переучивается. Ученые подчеркивают, что «корпоративное образование обцадает потенџиалом преодомения усугубцяюшегося разрыва базового образования и производственных запросов» [3, с. 147] .

Кроме того, процедуру нормирования труда надмежит законодательно отрегулировать на федеральном уровне посредством закрепления требований к соблюдению норм, ибо не исключена вероятность увеличения объемов производственных заданий со стороны работодателя. Тогда органы государственной власти вместе с профсоюзными организациями будут иметь возможность обеспечивать сощиальную защиту работников от повышения интенсивности труда, опираясь на законодательно закрепленные нормы.

Отметим, что на практике роль органов государственной власти в планировании роста производительности труда и в управлении данным проџессом в современных условиях пока ограничена. Органы государственного управления

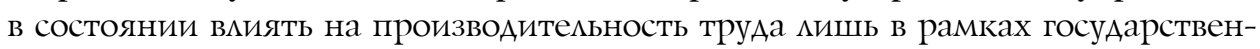
ных и муниципальных предприятий, субсидируя соответствующие программы, организуя необходимую дмя этого институциональную среду, принимая нужные законы, постановления и нормативы. Региональный масштаб полномочий органов власти обусмовлен распространением их компетенщии только на субъекты хозяйствования региона. 
На наш взгляА, сложившаяся ситуация не может быть оправдана необходимостью усиления самостоятельности субъектов хозяйствования при управлении производительностью труда в условиях конкуренции. Процесс разработки программ по повышению производительности труда с привлечением поА них инвестиций должен получить широкое распространение и на государственном уровне, с обязательным контролем их реализации на уровне регионов. Это особенно важно с позиџии стратегического управления, когда повышение производительности труда формирует условия Амя обеспечения расширенного воспроизводства и создает преАпосылки Амя экономического роста. Тем самым могут увеличиваться гарантии занятости населения через создание высокопроизводительных рабочих мест, Ааже несмотря на неизбежкность сокращения персонала на отдельных предприятиях.

С Аругой стороны, как пишет В.Ф. Потуданская, «в России ставится вопрос о необходимости сокращения продолжительности законодательно установленной рабочей недели, как одной из “антикризисных" мер. Казалось бы... это приведет к улучшению здоровья работников, больше времени будет уделяться семье, возрастут возможности повышения квалификационного уровня. < ..> на практике эта мера означает уменьшение заработной платы, сокращение занятости работающего населения» [4] .

Аумается, на сокрашение занятости следует ориентироваться в малоэффективных производствах, где налиџо технологическая отсталость и отсутствие инвестиций, что обеспечит перераспредемение мобильных и производительных трудовых ресурсов в отраслях экономики, обладающих наибольшим потенциалом экономического роста.

Следовательно, разработка государственных программ по оказанию поддержки роста производительности труда должна иметь последовательный характер: по завершении разработки программ субъектами хозяйствования смедует в соответствии с ними скорректировать соответствующие отраслевые программы, которые станут основой для корректировки региональных программ. В свою очередь, региональные программы домжны послужить основой Аля корректировки федеральной программы, которая и будет контролироваться органами исполнительной власти на федеральном уровне, а исполняться в регионах, отраслях и на предприятиях.

Основным документом, определяющим стратегические ориентиры в направлении повышения производительности труда, стал Указ Президента РФ от 7 мая 2012 г. № 596 «О долгосрочной госуАарственной экономической помитике». В дополнение к нему 9 июля 2014 г. Правительство России утверАило П^ан мероприятий по обеспечению повышения производительности труда, создания и модернизации высокопроизводительных рабочих мест.

Аанный план включает в себя следующие направления: стимулирование инвестиций Аля обновления и модернизации производства; технологическое обновление; замену устаревших рабочих мест; создание условий дяя профессионального развития работников; меры по повышению мобильности трудовых ресурсов; меры по росту производительности труда в компаниях с государственным участием; создание условий дмя увеличения занятости в сферах индивидуального и малого преАпринимательства [5] . 
Актуальность такого шага Правительства РФ обусловлена тем, что наблюдающееся в последние годы снижение динамики производительности труда в стране обостряет проблему преодоления до 2018 г. отставания в уровне производительности труда Российской Федерации от экономически развитых стран, что крайне важно дмя сохранения потенџиала экономического роста.

Вместе с предложенными в данном плане и реализуемыми в настоящее время мероприятиями представляется необходимым параммельно проводить институциональные реформы и структурную перестройку экономики страны. Институциональные реформы должны быть ориентированы на сокращение транзакционных издержек и перераспределение трудовых ресурсов в ключевых отраслях экономики на основе сокрашения в них занятости. Сегодня в стране нет научных и методических организаций, ориентированных на повышение производительности труда. Кроме того, в народном хозяйстве практически не осталось профессионалов, владеющих методикой нормирования труда и имеющих опыт в вопросах повышения его произвоАительности, так как высшие учебные заведения уже не выпускают таких специалистов.

В свою очередь, структурная перестройка экономики и активизация реамизации инфраструктурных проектов становятся неизбежны, поскольку рост производительности труда служит катализатором не только роста экономики, но и повышения уровня жизни граждан страны, увеличения доходной части бюджетов всех уровней, размера пенсий и заработной платы в бюджетной сфере. Особое внимание органы государственной власти домжны обратить на такой резерв роста производительности труда как обновление основных фондов, поскольку дия структурной перестройки экономики страны недопустима ситуация, когда предприятия многих отраслей демонстрируют высокую степень износа основных фондов (табл. 1) [6, с. 68]. Аинамика инвестиџий в основной капитал также демонстрирует низкие темпы (табц. 2) [6, c. 445].

Отметим, что Ааже медменный прирост инвестиций в основной капитал способен обеспечивать опережающие темпы производительности труда. ОАнако высокая изношенность основных фондов вызывает появление сомнений в эффективности привлечения инвестиџий в основной капитах. Отсюда нарушается связь между затратами труда и его оплатой, поскольку работа персонала преАприятий на изношенных среАствах производства во многих случаях требует опматы сверхурочных работ.

Аля реализации правительственного плана мероприятий по обеспечению повышения производительности труАа, создания и модернизаџии высокопроизводительных рабочих мест требуется действенная методика идентификаџии таких рабочих мест. Методика Росстата по расчету показателя «Прирост высокопроизводительных рабочих мест, в процентах к предыдущему году», рекомендованная к применению Минэкономразвития России, относит к высокопроизводительным рабочим местам все замешенные рабочие места предприятия, где среднемесячная заработная плата работни-

24 Bulletin of the Volga Region Institute of Administration • 2017. Vol. 17. № 5 
ков равна ици превышает установленную вецичину порогового значения. Критерием отбора самих предприятий, создавших такие рабочие места, служит «пороговое значение среднемесячной заработной платы работников на одно замещенное рабочее место, Аифференцированное по типам преАприятий и субъектам РФ». ОАнако, как показывает практика, высокий уровень заработной платы не всегда становится гарантией высокой произвоАИтельности труАа.

Таблища 1

Степень износа основных фондов (на конец года, \%), по годам

\begin{tabular}{l|c|c|c|c|c|c|c}
\hline \multicolumn{1}{c|}{ Показатель } & 2005 & 2010 & 2011 & 2012 & 2013 & 2014 & 2015 \\
\hline Все основные фонды & 43,5 & 47,1 & 47,9 & 47,7 & 48,2 & 49,4 & 50,5 \\
Строительство & 42,3 & 48,3 & 47,5 & 49,0 & 50,0 & 51,2 & 53,5 \\
Транспорт и связь & 51,4 & 56,4 & 57,2 & 56,2 & 56,5 & 58,3 & 59,1 \\
Добыча полезных ископаемых & 54,8 & 51,1 & 52,2 & 51,2 & 53,2 & 51,8 & 56,3 \\
Рыболовство, рыбоводство & 57,4 & 64,7 & 65,9 & 65,1 & 64,4 & 58,9 & 57,9
\end{tabular}

Инвестиџии в основной капитац, по годам

Таблица 2

\begin{tabular}{l|c|c|c|c|c|c|c}
\hline \multicolumn{1}{c|}{ Показатели } & 2005 & 2010 & 2011 & 2012 & 2013 & 2014 & 2015 \\
\hline $\begin{array}{l}\text { Инвестиции в основ- } \\
\text { ной капитал в факти- } \\
\text { чески действовавших } \\
\text { ценах, млрд руб. }\end{array}$ & 3611,1 & 9152,1 & 11035,7 & 12586,1 & 13450,2 & 13902,6 & 14555,9
\end{tabular}

Представмяется, что при отсутствии четкого критерия оџенки высокопроизводительного рабочего места региональные власти будут склонны предоставлять информаџию о создании таких мест обычным суммированием всех сформированных рабочих мест применительно к различным программам. Кроме того, Аействиям по исполнению направцений указанного пцана в настоящее время весьма сложно Аать оџенку, так как на веб-сайтах ответственных органов государственной власти информаџии о реализации запланированных мероприятий крайне мало. Нет данных о Аостижении целевых значений по направлениям плана, отсутствует конкретика в определении сфер, где должны создаваться высокопроизводительные рабочие места. Например, в соответствии с планом бюджетная сфера также рассматривается при определении числа созданных высокопроизводительных рабочих мест, однако она напрямую не вцияет на рост производительности труда в экономике.

Особое внимание необходимо обратить на аттестащию существующих рабочих мест в цемях выявления их вкмада в общий успех организаџии или предприятия. Если он не обнаруживается ими минимален, то такие рабочие 
места следует миквидировать как препятствующие росту экономики. В Аополнение к реализуемому плану целесообразно предложить еще ряд мероприятий.

Прежде всего следует обратить внимание на стимулирование инвестирования, направленного на обновцение и модернизаџию производства, ибо низкая Аоступность кредита вследствие высоких процентных ставок и тяжелых залоговых требований выступает серьезным ограничением инвестиционного роста и, как следствие, роста производительности труда.

В Аанном направлении требуется активизировать в регионах работу по развитию соответствующей инфраструктуры: индустриацьных парков и технопарков; информационных центров Аля инвесторов с аккумулированием в них информации о приоритетных направлениях развития региона и о планируемых к реализации инвестиционных проектов; спещиальных подразделений, осуществляющих экспертную оценку инвестиционных проектов; банковских структур и организаций по страхованию рисков.

Подчеркнем, что инвесторы проявляют интерес только к тем проектам, результаты реацизаџии которых будут иметь устойчивый потребительский спрос. Следовательно, перевооружение целесообразно там, где производится востребованная на рынке продукция, чтобы обеспечить рост рыночного предложения за счет роста производительности труда. Поэтому многим руководителям отечественных предприятий необходимо развивать маркетинговое мышление, требуемое при разработке инвестиционных проектов. Важно развивать системы переподготовки кадров и создавать условия Аля профессионацьного роста исполнителей на основе распространения переАового опыта и технологий в рамках проведения соревнований и профессиональных чемпионатов.

По нашему мнению, именно недостаток внутренних стимулов к повышению производительности труда выступает камнем преткновения в обеспечении роста российской экономики. Кроме того, причиной низкой производительности труда служит функщионирование большинства отечественных предприятий только на регионацьных рынках, что приводит к отсутствию стимулов к инновационной деятельности.

Персоналу предприятий и организаций важно знать, что продукция будет иметь спрос и, следовательно, принесет прибыль: больше продукции - больше прибыли. ОАнако при имеющемся спросе на продукщию, многие отечественные производители и продавцы повышают на нее цены вместо инвестирования в развитие производства и увеличения объемов. Как следствие, повышения производительности труда не достигается.

В настоящее время органам государственного управления необходимо широко пропагандировать работу фонда развития отечественной промышленности, направленную на предоставление предприятиям цьготных кредитов из данного фонда. Такая информация будет способствовать как совершенствованию механизма отбора субъектов хозяйствования Аця преАоставцения им возможности получения мьготного кредита, так и обеспечит условия Аця развития производственного предпринимательства, организации технопарков 
и индустриальных парков, которые будут катализатором создания новых высокопроизводительных рабочих мест.

Сегодня практически все субъекты РФ имеют незанятые промышленные плошадки с производственной инфраструктурой, которые можно использовать Аля организации работы технопарков и индустриальных парков. Важно, чтобы региональные власти осуществмяли мониторинг таких свободных площадок, ибо это необходимо не только Аля трудоустройства персонала, высвободившегося при Аиквидации рабочих мест, но и Аля привлечения профессионалов из Аругих регионов. В данном случае нужны соответствующие региональные программы, обеспечивающие трудовую мобильность насемения на основе формирования фондов мьготного арендного жилья, упрошения трудоустройства вАали от основного места проживания, Аьготных проезАов ААя этой категории граждан. Например, можно за счет предоставления возможности снижения единого социального налога создавать на предприятиях соответствующий фонА, позволяющий привлекать нужных спещиалистов из Аругих регионов, оплачивать им проезА и аренду жилья, выдавать ссуду на обустройство жилья и т.п.

Еще оАним мероприятием может быть стимулирование технологического обновления в отраслях экономики на основе кмастерных форм организации хозяйственной практики, поскольку Аля поддержания инновационной Аеятельности в большинстве отраслей требуется высокий уровень динамики технологического обновления.

Как справедииво отмечает О.П. Гаршина, «инновации тесным образом связаны с ростом производительности труаа, хотя внеАрение их в производственный процесс сопровождается существенными финансовыми затратами, делая их малопривлекательными в краткосрочном периоде. Более того, требуется опредеменное время дмя освоения новшества и адаптации персонала к новым усмовиям работы, что первоначально, как правило, снижает темпы роста производительности труда. Изможенные обстоятельства вызывают необходимость более подробного исследования взаимосвязи инноваџий и производительности труда. Раздичные виды новшеств, относящиеся к технике и технологиям, к формам организации производства и управлению, тесно взаимосвязаны между собой. ОАнако дмя промышленных предприятий, и в особенности дмя предприятий машиностроения, первостепенное значение имеют технико-технологические инноваџии, так как именно они служат основой технологического прогресса и технологического перевооружения производства, создают преАпосылки для внеАрения всех Аругих видов инноваций, в том числе и продуктовых. БАагодаря их внеАрению может быть обеспечен выпуск:

- большего объема продукции при неизменных издержках производства;

- неизменного объема продукции с существенным снижением издержек производства;

- большего объема продукщии с существенным снижением издержек производства;

- более качественной продукции» [7, с. 20]. 
В формировании действенной инновационной среды основная роль должна быть отведена именно органам государственной власти, так как они обязаны разрабатывать и обеспечивать реализаџию инновационной политики, в рамках которой могут решаться разцичные задачи. Прежде всего это задача по аккумулированию средств на научные исследования и инноваџионные разработки посредством перераспределения в рамках бюджета мибо формирования соответствующих фондов.

$\triangle$ Аалее требуется формирование единого технологического пространства на уровне регионов посредством оказания содействия развитию межотраслевой и внутриотраслевой коопераџии, а также определения общих стратегических векторов для инноваџионных проџессов. Решение такой задачи будет способствовать созданию эффективной национальной инновационной системы, базируемой на совокупности государственных и частных институтов, обеспечивающих инновационную деятельность.

Важной задачей представляется стимулирование инновационной деятельности, Аля решения которой необходима совершенная правовая база, направленная на защиту прав интемеектальной собственности и страхование инновационных рисков, на регулирование деятельности предприятий и организаций научно-инноваџионной инфраструктуры, на создание и развитие структур, осуществцяющих научно-исследовательские и опытно-конструкторские работы в отраслях государственного сектора экономики.

Особое внимание следует уделить стимулирующей функщии налогов, и, прежде всего, налога на прибыль, изменение которого домжно иметь отношение к величине его ставки и проџедуре взимания. Аанная процедура может базироваться на введении дифференцированных налоговых ставок в зависимости от того, каким образом зарабатывается прибыль субъектами хозяйствования. Если прибыль получена в результате снижения издержек производства, повышения его эффективности и роста производительности труда, то к такому предприятию обычно применяется низкая ставка налога на прибыль. При получении прибыли на выпускаемую продукцию в результате роста џен, что неизбежно приводит к увеличению инфмяџии, преАприятие Аолжно будет платить повышенную ставку налога на прибыль. Подобный механизм цемесообразно использовать и Аля поощрения инновационной и инвестиџионной деятельности, что обеспечит сокращение безработиџы и создаст условия дмя организации высокопроизводительных рабочих мест.

Раџионально также со стороны органов вмасти ввести санкции для преАприятий, производящих устаревшую продукцию и обеспечивать работу по привлечению в страну перспективных иностранных производств. Органы государственного управления должны постоянно осушествцять широкомасштабную пропаганду достижений в научно-технической и инноваџионной сфере и стимулировать такие достижения соответствующими премиями в обкасти науки и техники.

Решение перечисленных задач и осушествление мероприятий будет способствовать росту конкурентоспособности продукщии отечественных преА- 
приятий, ее востребованности не только на национальном, но и зарубежных рынках и, как следствие, повышению производительности труда.

В настоящее время все больше субъектов хозяйствования осушествляют разАичные меры по повышению производительности труда. ОАнако такой инАивидуальный подхоА к решению этой непростой задачи не всегда обеспечивает нужный результат. Без государственной поддержки, поддержки общественных и профессиональных объединений, которые своей работой способствовали бы поиску и внеАрению передового опыта, и методов в Аанном направлении, сложно переломить ситуацию с производительностью труда.

Общероссийская общественная организация малого и среднего преАпринимательства «Опора России» совместно с Общественным объединением по повышению производительности труда, которое объединимо в себе успешный опыт более 600 российских преАприятий, повысивших производительность труда от Авух до четырех раз, подготовияа и предложила программу повышения производительности труда и роста экономики России, которая подверглась научной экспертизе в комиссии по повышению производительности труда Российской Академии Наук. Ее авторы утвержАают, что программы роста экономики, предложенные Правительством РФ, Столыпинским клубом и Центром стратегического развития, не могут обеспечить нужного результата, так как не ориентируют на конкретные меры по повышению производительности труда в стране, без которых все остальные мероприятия, направленные на рост экономики, тщетны.

Основным тезисом предложенной программы стало утверждение о том, что производительность труда не может расти сама по себе - в этом проџессе обязательно участие государства, прямой задачей которого должно стать формирование парадигмы высокопроизводительной культуры и эффективного производства. ПреАложено создать специальную структуру - Наџиональный комитет по повышению производительности труда.

В настоящее время во многих государствах созданы национальные структуры по повышению производительности труда, которые имеют различные названия: национальные центры по повышению производительности труда, инновационные центры развития бизнеса, ассоџиации повышения производительности труда. Эти структуры возглавмяются представителями высшей иерархии государственного управления, что свидетельствует о важности решаемых ими задач.

В Германии, например, рационализаторский и инновационный центр развития бизнеса, созданный в 1921 г. по инициативе Министерства экономики и Ассоџиации немеџких инженеров, стал одной из первых в мире организаций, системно занимающихся изучением и внеАрением передового опыта в деле повышения производительности труда. Эта некоммерческая организация проводит анализ методик повышения производительности труда, оказывая методологическую и организационную поддержку малым и средним преАприятиям. Она организует Аля них обучение и консультации по внеАрению инноваций и развитию стартапов. В регионах страны имеются так называемые центры производительности труда, финансируемые из 
государственного бюджета и также помогающие предприятиям бизнеса повышать свою конкурентоспособность через повышение производительности труаа [8].

Большое внимание таким вопросам удемяется и в Японии. Именно на производительности и эффективности во многом концентрируются системы обучения и развития профессиональных навыков, благодаря чему Япония по уровню производительности труда и темпам ее роста занимает одно из ведущих мест в мире. Производительностью труда здесь занимаются Министерство труда, Японская ассоџиаџия МОТ и Японский центр производитеиьности труда Аля соџиально-экономического развития. Залогом высокой производительности в Аанном центре считается создание благоприятных условий труда, ориентированных на работника и способствующих эффективной работе. Именно поэтому в своих программах эта организация фокусируется на поддержании сощиальной справедливости и прозрачности, стимулировании устойчивого роста промышленных предприятий и развитии. Гцавные задачи, которые центр ставит переА собой с учетом новых экономических вызовов, состоят в разработке программ повышения производительности с учетом «старения» каАров, в углублении взаимопонимания межАу работниками и предпринимателями, в совместном владении информацией, в Аальнейшей работе по поиску и внедрению современных технологий повышения произвоАительности [8] .

Аля большей эффективности и содействия обмену опытом и мучшими практиками национальные центры стали объединяться в международные ассоџиации. Аве крупнейшие из них - это европейская и азиатская.

Европейская ассоциация повышения производительности труда была основа в 1966 г. в качестве преемника ранее существовавшего Европейского агентства продуктивности. В ее состав входят национацьные центры производительности труда Австрии, Бельгии, Великобритании, Германии, Италии, Кипра, Нилерландов, Польши, Румынии, Словакии, Турџии, Финцяндии и Чехии. Ассоциация обеспечивает не только обмен опытом между своими чиенами, но и объединяет совместные усимия по подготовке проектов комлективных договоров и на уровне отдельных преАприятий и трудовых комлективов, и на федеральном и региональном уровнях. Она содействует занятости насемения путем повышения производительности труда, подАержки новых форм занятости, развития профессиональных навыков и квалификации, предотвращения неАобросовестной конкуренции.

Азиатская ассоџиаџия повышения производительности труда была основана в 1961 г. как правительственная некоммерческая организация Аля соАействия устойчивому соџиацьно-экономическому развитию Азии и стран Тихоокеанского региона. В нее входят Бангладеш, Гонконг, Индия, Индонезия, Иран, Камбоджа, Китай, Ааос, Махайзия, Монголия, Непац, Пакистан, Сингапур, Фиджи, Филиппины, Шри-Аанка, Южная Корея, Япония. Главная цель Азиатской ассоциации состоит в изучении, разработке и внедрении переАовых методов повышения производительности труда с учетом экономических условий и трансформаций, происходящих в странах-участницах, в стимулиро- 
вании обмена опытом, в обучении и повышении компетенций национальных центров производительности [8] .

В Российской Федерации органы исполнительной власти должны поставить переА собой задачу по стимулированию производительности труда, оказанию помощи субъектам Федерации по обмену передовым производственным опытом, реализации на предприятиях инновационных программ и программ модернизации основных фондов, созданию действенных систем переподготовки и обучения персонала. На государственном уровне необходимо поставить перед Министерством образования и науки РФ цемь, направленную на возобновление в вузах подготовки специалистов по нормированию труда, что позвомит профессионально координировать проџесс повышения производительности труда в рамках всех субъектов хозяйствования, во всех субъектах РФ и на территории страны в целом.

Аля решения такой масштабной и сложной задачи требуется также подАержка и активная позиџия представителей отечественного бизнеса, которым следует наладить обратную связь с органами государственной власти страны, объединить свои усилия в данном направлении и придать импульс широкому обмену передовым опытом в деле повышения произвоАительности труаа.

\section{Библиографический список}

1. Цыганков В.А. Эволюция подходов к оценке эффективности труда в современной экономике // Бизнес. Образование. Право. Вестник Волгоградского института бизнеса. 2014. № 1. (26). С. 110-112.

2. Косицына Ф.П. Соотношение роста производительности труда и заработной платы критерий эффективности государственного регулирования экономики // Бизнес. Образование. Право. Вестник Волгоградского института бизнеса. 2010. № 2 (12). С. 19-23.

3. Сулакшин С.С., Багдасарян В.Э., Колесник И.Ю. Государственное управление в России и труд. Оплата, мотивация, производительность. М., 2010.

4. Потуданская В.Ф. Продолжительность рабочего времени: отечественный и зарубежный опыт // Бизнес. Образование. Право. Вестник Волгоградского института бизнеса. 2014. № 2 (27). С. 59-65.

5. План мероприятий по обеспечению повышения производительности труда, создания и модернизации высокопроизводительных рабочих мест: Распоряжение Правительства РФ № 1250-р от 9 июля 2014 г. (с изм. от 30 дек. 2015 г.). URL: http://www.garant.ru/products/ipo/ prime/doc/70594184/

6. Россия в цифрах. 2016: Краткий статистический сборник / Росстат. М., 2016.

7. Гаршина О.П. Влияние инноваций на рост производительности труда промышленных предприятий // Вестник СамГУ. 2011. № 16 (87). С. 19-25.

8. Производительность труда: государственные программы и общественные инициативы. URL: http://www.up-pro.ru/library/production_management/productivity/gosprogrammy.html 